\title{
Recurrent Chronic Myelogenous Leukemia, BCR-ABL1 Positive
}

National Cancer Institute

\section{Source}

National Cancer Institute. Recurrent Chronic Myelogenous Leukemia, BCR-ABL1 Positive. NCl Thesaurus. Code C9070.

The reemergence of chronic myelogenous leukemia after a period of remission. 